\title{
Prophylactic Antiemetics for Haematological Malignancies: Prospective Nationwide Survey Subset Analysis in Japan
}

\author{
ISAO YOSHIDA ${ }^{1}$, KAZUO TAMURA ${ }^{2,3}$, TOSHIHIRO MIYAMOTO ${ }^{4}$, MOTOTSUGU SHIMOKAWA $^{5}$, \\ YASUSHI TAKAMATSU ${ }^{3}$, YASUHITO NANYA ${ }^{6}$, ITARU MATSUMURA ${ }^{7}$, MORITAKA GOTOH $^{8}$, \\ TADAHIKO IGARASHI ${ }^{9}$, TSUTOMU TAKAHASHI ${ }^{10}$, KEISUKE AIBA $^{11}$, KYOYA KUMAGAI $^{12}$, \\ KENICHI ISHIZAWA ${ }^{13}$, NAOKI KURITA ${ }^{14}$, NORIKO USUI ${ }^{15}$ and KIYOHIKO HATAKE ${ }^{16}$ \\ ${ }^{1}$ Department of Hematologic Oncology, National Hospital Organization Shikoku Cancer Center, Matsuyama, Japan; \\ ${ }^{2}$ General Medical Research Center, Fukuoka University, Fukuoka, Japan; \\ ${ }^{3}$ Division of Medical Oncology, Hematology and Infectious Disease, Fukuoka University, Fukuoka, Japan; \\ ${ }^{4}$ Department of Medicine and Biosystemic Science, Kyushu University Faculty of Medicine, Fukuoka, Japan; \\ ${ }^{5}$ Clinical Research Institute, National Hospital Organization Kyushu Cancer Center, Fukuoka, Japan; \\ ${ }^{6}$ Department of Hematology and Oncology, The University of Tokyo, Tokyo, Japan; \\ ${ }^{7}$ Department of Hematology and Rheumatology, Kindai University Faculty of Medicine, Osakasayama, Japan; \\ ${ }^{8}$ Department of Hematology, Tokyo Medical University, Tokyo, Japan; \\ ${ }^{9}$ Hematology/Oncology Division, Gunma Prefectural Cancer Center, Ohta, Japan; \\ ${ }^{10}$ Department of Oncology/Hematology (Department of 3rd Internal Medicine), \\ Cancer Center, Shimane University, Izumo, Japan; \\ ${ }^{11}$ Division of Clinical Oncology/Hematology, Department of Internal Medicine, \\ Jikei University School of Medicine, Tokyo, Japan; \\ ${ }^{12}$ Division of Hematology-Oncology, Chiba Cancer Center, Chiba, Japan; \\ ${ }^{13}$ Department of Hematology and Rheumatology, Tohoku University Graduate School of Medicine, Sendai, Japan; \\ ${ }^{14}$ Department of Hematology, Faculty of Medicine, University of Tsukuba, Tsukuba, Japan; \\ ${ }^{15}$ Department of Clinical Oncology and Hematology, The Jikei University Daisan Hospital, Tokyo, Japan; \\ ${ }^{16}$ Department of Hematology Oncology, The Cancer Institute Hospital of JFCR, Tokyo, Japan
}

\begin{abstract}
Background/Aim: Although neurokinin-1 receptor antagonists are approved chemotherapy drugs in Japan, no nationwide surveys have been performed to validate chemotherapy-induced nausea and vomiting (CINV) guidelines in clinical practice. This study evaluated CINV in patients with haematological malignancies starting first-time chemotherapy. Patients and Methods: A nationwide CINV survey on patients with haematological malignancies was conducted at 118 institutions. Patients undergoing moderately emetic chemotherapy $(n=17)$ and highly emetic chemotherapy
\end{abstract}

This article is freely accessible online.

Correspondence to: Isao Yoshida, Department of Hematologic Oncology, National Hospital Organization Shikoku Cancer Center, 160 Kou Minamiumemotomachi, Matsuyama, Ehime 791-0280, Japan. Tel: +81 899991111, e-mail: iyoshida-md@umin.ac.jp

Key Words: Antiemetic, chemotherapy-induced nausea and vomiting, CHOP therapy, haematological malignancies.
(HEC; $n=180)$ were compared. Results: Forty-one patients undergoing HEC received triple antiemetics. Female gender and young age were risk factors for early-phase nausea, while female gender remained a risk factor for late-phase nausea and vomiting. Among 125 patients receiving CHOP (doxorubicin, cyclophosphamide, vincristine, prednisone)-like regimens, complete response and complete control were increased in patients receiving triple antiemetics, compared to those with double antiemetics. Conclusion: Guideline compliance was very low. Although not statistically significant, there was a trend for reduced CINV and improved disease control for triple versus double antiemetics, suggesting that triple antiemetics should be considered for HEC, especially in young female patients with non-Hodgkin lymphoma receiving $\mathrm{CHOP}$-like regimens.

One of the most clinically significant adverse events in cancer patients undergoing chemotherapy is chemotherapy-induced nausea and vomiting (CINV), which not only makes patients subjectively sick, but also decreases their oral intake, leading to dehydration and malnutrition. These negative impacts lead 
to prolonged treatment intervals and low relative-dose intensities of antineoplastic agents, usually resulting in poor treatment outcomes (1). While combination chemotherapy regimens have improved treatment outcomes, many patients develop severe CINV that can deter their drive to continue chemotherapy, resulting in lower tumour responses with poorer outcomes. Since lymphomas and leukaemias are potentially curable haematological disorders, CINV control is considered to play a vital role in supportive care (2).

Since triple antiemetic regimens $\left[5 \mathrm{HT}_{3}\right.$ receptor antagonist $\left(5 \mathrm{HT}_{3} \mathrm{RA}\right)$, neurokinin-1 receptor antagonist (NK1RA), and dexamethasone] became available in Japan in 2010, CINV, especially vomiting, has appeared to be under control (3). However, nausea has remained a significant side effect, associated with both highly emetogenic chemotherapy (HEC) and moderately emetogenic chemotherapy (MEC) (4). Compared with intermittent administration of 1-day chemotherapy for solid tumours, acute leukaemia is usually treated with antileukaemic agents for 7-10 consecutive days (5). Conversely, the standard regimen for lymphomas is CHOP (cyclophosphamide, doxorubicin, vincristine, and prednisolone) (6), which contains a high dose of glucocorticoid and is given to patients for 5 days. As few prospective clinical studies have been performed to evaluate antiemetic measures against CINV in these settings $(7,8)$, the antiemetic guidelines for CINV including the Japanese guidelines (3) have proposed only consensus-based recommendations. It is especially difficult to manage CINV induced by daily administration of antineoplastic agents.

We conducted a nationwide prospective registry survey on the management of CINV after the first version of the Japanese guideline was published in 2015 (9-12). We herein report the results of a subset analysis of patients with haematological malignancies.

\section{Patients and Methods}

Study design. The details of the present study can be found in our previous report (9). Briefly, the study was a multicentre, prospective registry organized by the CINV Study Group of Japan and included 118 institutions in Japan. The protocol was registered in the UMIN CTR (UMIN000005971), was approved by the institutional review board at each study site, and written informed consent was provided by all patients prior to initiation of the study. Patients who were scheduled to undergo first-time treatment with HEC or MEC were registered. The emetogenic risk of the chemotherapeutic agents was classified in accordance with the Japanese guidelines (3).

Background characteristics of the patients, including initials, sex, birth date, type and stage of cancer, alcohol use, history of motion sickness, presence or absence of pregnancy, morning sickness, and other eligibility criteria were collected. Early-phase CINV was defined as nausea and vomiting observed at $<24 \mathrm{~h}$ after initiation of chemotherapy, and late-phase CINV was defined as nausea and vomiting observed at $\geq 24 \mathrm{~h}$ after initiation of chemotherapy.
To assist in collection of data regarding CINV, all patients were instructed to record onset and severity of nausea, frequency of vomiting, number of salvage treatments, food intake, and number of hospitalizations and/or outpatient visits in a 7-day diary prior to initiation of chemotherapy.

Antiemetic use and effects. A double antiemetic regimen comprising $5 \mathrm{HT}_{3} \mathrm{RA}$ and dexamethasone for MEC and a triple antiemetic regimen comprising $5 \mathrm{HT}_{3} \mathrm{RA}$, dexamethasone, and aprepitant for HEC are recommended in the Japanese guidelines for CINV. To assess the antiemetic effects, complete response (CR) and complete control (CC) were evaluated. CR was defined as no emetic episodes and no rescue antiemetic measures in the early phase, late phase, or overall study period, whereas CC was defined as no vomiting, rescue therapy measures, or nausea in any phase.

Data analysis. A summary of the descriptive statistics was obtained to analyse the patient demographic characteristics and survey responses. The risk factors for early-phase and late-phase nausea and vomiting were analysed by univariate and multivariate logistic regression analyses; odds ratios (ORs) and 95\% confidence intervals (CIs) were estimated. Two-sided $p$-values were calculated, and $p<0.05$ was accepted as statistically significant. SAS version 9.4 (SAS Institute, Cary, NC) was utilized for all statistical analyses.

\section{Results}

Patient characteristics. A total of 2,068 patients were registered between April 2011 and December 2012, of whom 1,910 patients with sufficient information were included in the analyses. Only patients with haematological malignancies were included in the present study. A total of 197 patients with haematological malignancies who underwent HEC or MEC during the study period were identified.

The patients' baseline characteristics are summarized in Table I. Of the 197 patients, 109 were male with a median age of 61.0 years $($ range $=22-87)$ and 88 were female with a median age of 62.5 years (range $=22-87$ ). The underlying diseases were HL in 8 patients, non-HL (NHL) in 140, multiple myeloma in 11, and acute leukaemia in 38. Overall, 180 patients (91\%) received HEC and 17 patients (9\%) received MEC. The performance status was good (0-1) in most patients. The disease was at an advanced stage in the majority of patients, with the exception of those with HL.

HEC mainly consisted of a CHOP-like regimen in patients with lymphomas and a DC (daunorubicin/idarubicin plus cytarabine)-like regimen in patients with leukaemias (Table II). As only 17 patients received MEC, the analyses of MEC were too limited to obtain meaningful conclusions. Therefore, the results for patients with lymphomas and some patients with leukaemias were mainly analysed.

Use of antiemetics. Among the patients treated with HEC, $5 \mathrm{HT}_{3} \mathrm{RA}$ and dexamethasone (double antiemetic regimens) were administered to 104 patients $(57.8 \%)$, while double antiemetic regimens plus NK1RA and aprepitant (triple 
Table I. Characteristics of patients with haematological malignancies who received HEC or MEC.

\begin{tabular}{|c|c|c|c|c|}
\hline & $\begin{array}{l}\text { Hodgkin lymphoma } \\
\qquad(\mathrm{n}=8)\end{array}$ & $\begin{array}{l}\text { Non-Hodgkin lymphoma } \\
\qquad(\mathrm{n}=140)\end{array}$ & $\begin{array}{l}\text { Multiple myeloma } \\
\qquad(\mathrm{n}=11)\end{array}$ & $\begin{array}{l}\text { Leukaemia } \\
\quad(\mathrm{n}=38)\end{array}$ \\
\hline \multicolumn{5}{|l|}{ Characteristics } \\
\hline \multicolumn{5}{|c|}{ Age (years), median (range) } \\
\hline All & $38.5(26-68)$ & $63.5(22-87)$ & $62.0(49-69)$ & $57.0(22-80)$ \\
\hline Male:female ratio & $4: 4$ & $75: 65$ & $6: 5$ & $24: 14$ \\
\hline \multicolumn{5}{|l|}{ Stage } \\
\hline \multicolumn{5}{|l|}{ Primary } \\
\hline Stage I & 0 & 18 & 0 & NA \\
\hline Stage II & 6 & 24 & 3 & NA \\
\hline Stage III & 1 & 34 & 5 & NA \\
\hline Stage IV & 1 & 62 & NA & NA \\
\hline Relapse & 0 & 1 & 1 & 0 \\
\hline Unknown & 0 & 1 & 2 & 38 \\
\hline \multicolumn{5}{|c|}{ ECOG performance status } \\
\hline 0 & 5 & 79 & 8 & 25 \\
\hline 1 & 3 & 48 & 1 & 11 \\
\hline 2 & 0 & 11 & 2 & 2 \\
\hline 3 & 0 & 1 & 0 & 0 \\
\hline 4 & 0 & 1 & 0 & 0 \\
\hline HEC & 8 & 134 & 4 & 34 \\
\hline MEC & 0 & 6 & 7 & 4 \\
\hline
\end{tabular}

Except for age, data are presented as numbers of patients. ECOG, Eastern Cooperative Oncology Group; HEC, highly emetogenic chemotherapy; MEC, moderately emetogenic chemotherapy; NA, not applicable.

Table II. Regimen details for patients with haematological malignancies who received HEC or MEC.

\begin{tabular}{lrr}
\hline HEC regimen & $\mathrm{n}$ & $\%$ \\
\hline ABVD therapy & 8 & 4.4 \\
CHOP therapy & 108 & 60.0 \\
CHOP-like regimens & 21 & 11.6 \\
Other intensive regimens & 11 & 6.1 \\
Daunorubicin+cytarabine & 10 & 5.6 \\
Daunorubicin+cytarabine-like regimens & 18 & 10.0 \\
High-dose cyclophosphamide (cyclophosphamide at $\left.\geq 1500 \mathrm{mg} / \mathrm{m}^{2}\right)$ & 4 & 2.2 \\
Total & 180 & 100.0 \\
\hline MEC regimen & $\mathrm{n}$ & $\%$ \\
\hline VCD therapy & 7 & 41.1 \\
Others & 10 & 58.9 \\
Total & 17 & 100.0
\end{tabular}

ABVD, Doxorubicin, bleomycin, vinblastine, and dacarbazine; CHOP, cyclophosphamide, doxorubicin, vincristine, and prednisolone; HEC, highly emetogenic chemotherapy; MEC, moderately emetogenic chemotherapy; VCD, bortezomib, cyclophosphamide, and dexamethasone.

antiemetic regimens) were administered to 41 patients $(22.8 \%)$. Other antiemetics were administered to 35 patients $(19.4 \%)$.

Among the patients treated with MEC, double antiemetic regimens were administered to 8 patients, while triple antiemetics were administered to 5 and other antiemetics were administered to 4 .
CINV incidence and severity. As shown in Figure 1A, the incidence of vomiting among patients receiving HEC was quite low (4.4\% in early phase and $8.9 \%$ in late phase), while the incidence of nausea was higher $(18.9 \%$ in early phase and $38.9 \%$ in late phase).

The incidence of nausea in the early phase were $19.2 \%$ in patients treated with double antiemetics, $17.1 \%$ in patients 


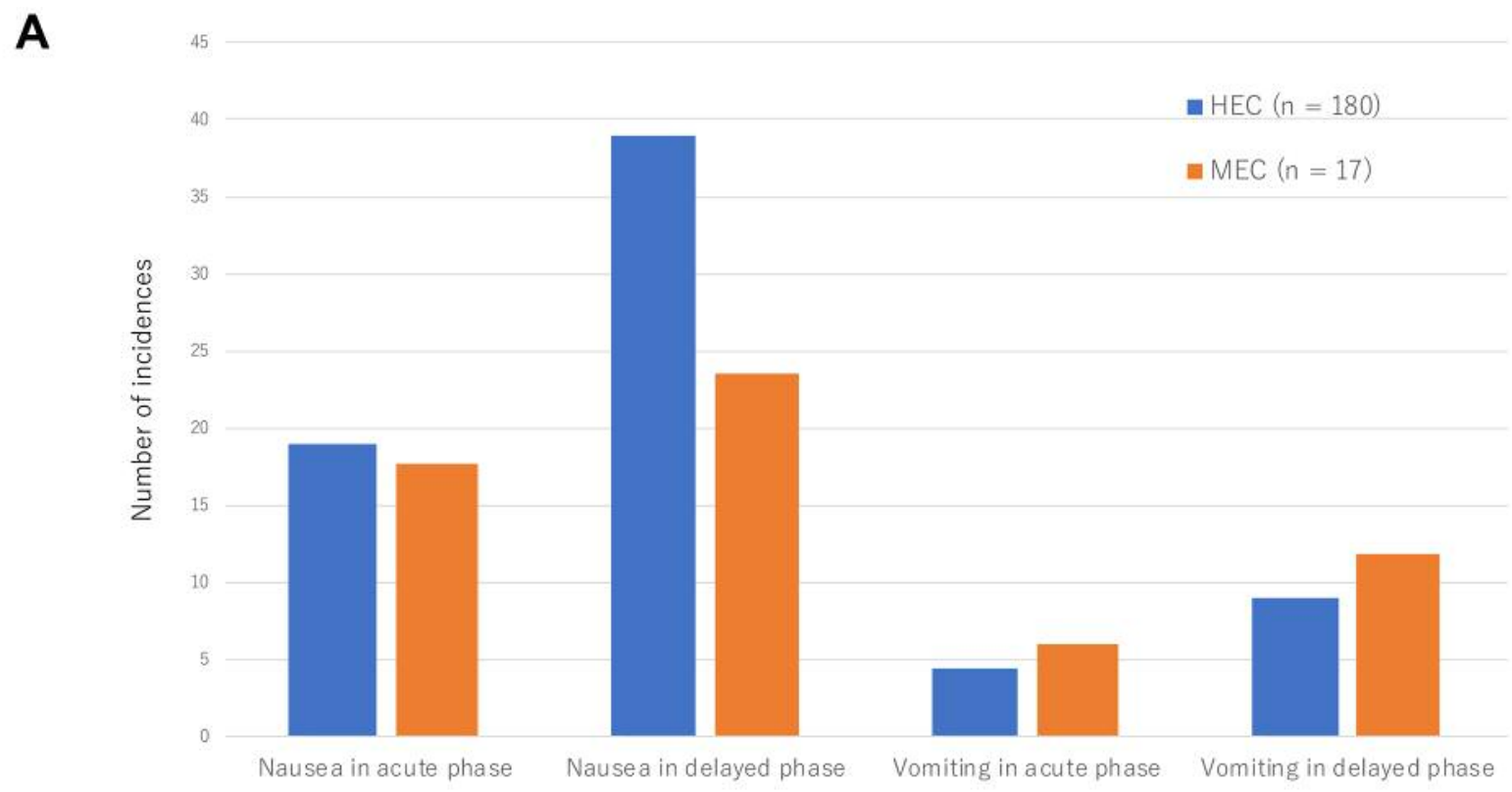

B

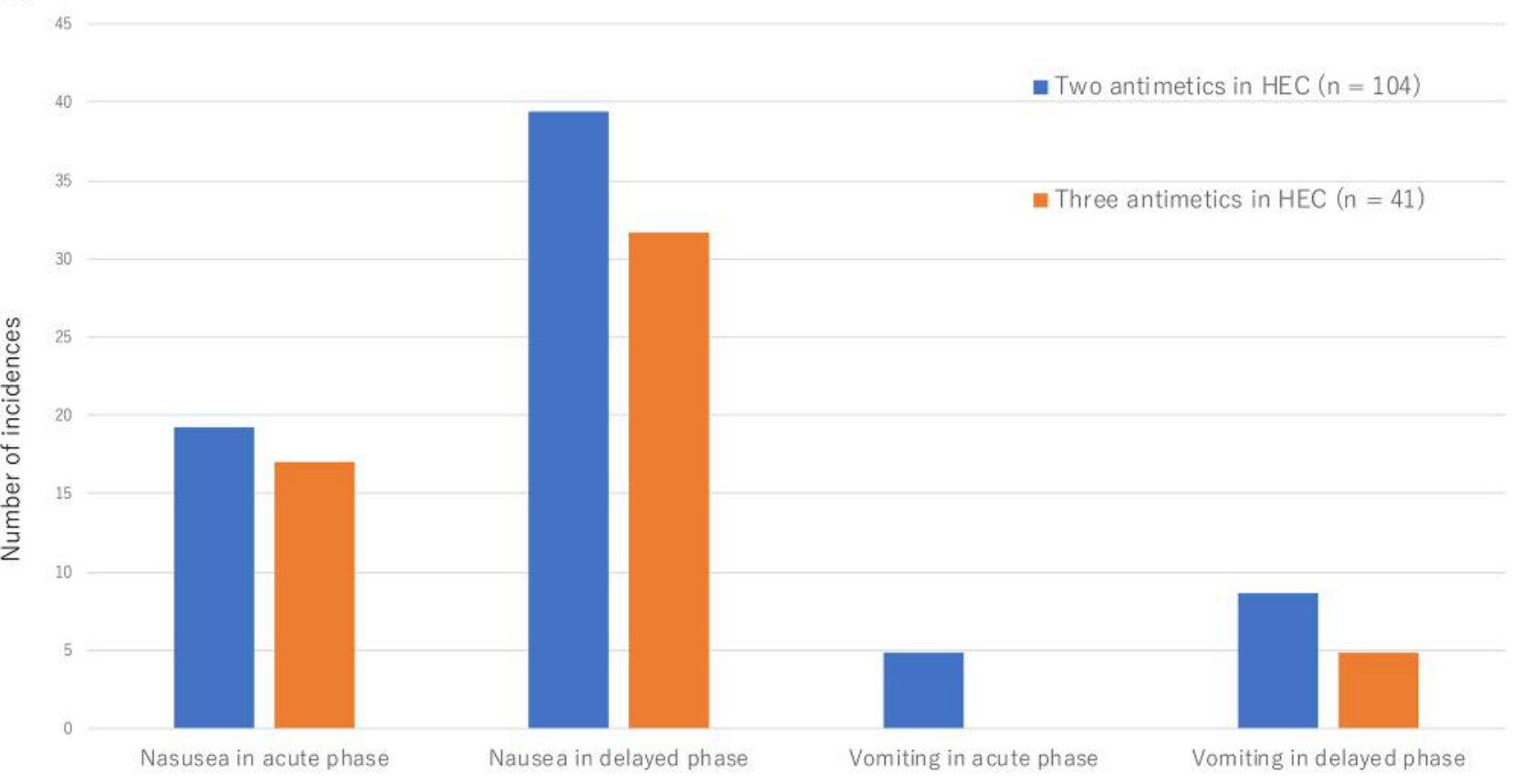

Figure 1. Incidence chemotherapy-induced early-and late-phase nausea and vomiting was compared between patients who received highly emetogenic chemotherapy (HEC) and moderately emetogenic chemotherapy (MEC) (A), as well as between patients who, besides HEC, received double antiemetic regimens $\left(5 \mathrm{HT}_{3}\right.$ receptor antagonist and dexamethasone) and triple antiemetic regimens $\left(5 H T_{3}\right.$ receptor antagonist, dexamethasone, and aprepitant) $(B)$.

treated with triple antiemetics $(p=0.8098)$. The incidence of nausea in the late phase were $39.4 \%$ in patients treated with double antiemetics, $31.7 \%$ in patients treated with triple antiemetics $(p=0.2285)$ (Figure 1B).
In patients that received CHOP therapy, the incidence of nausea in the early phase was $22.6 \%$ in patients treated with double antiemetics, $20.8 \%$ in patients treated with triple antiemetics $(p=0.8528)$. The incidence of nausea in the late 


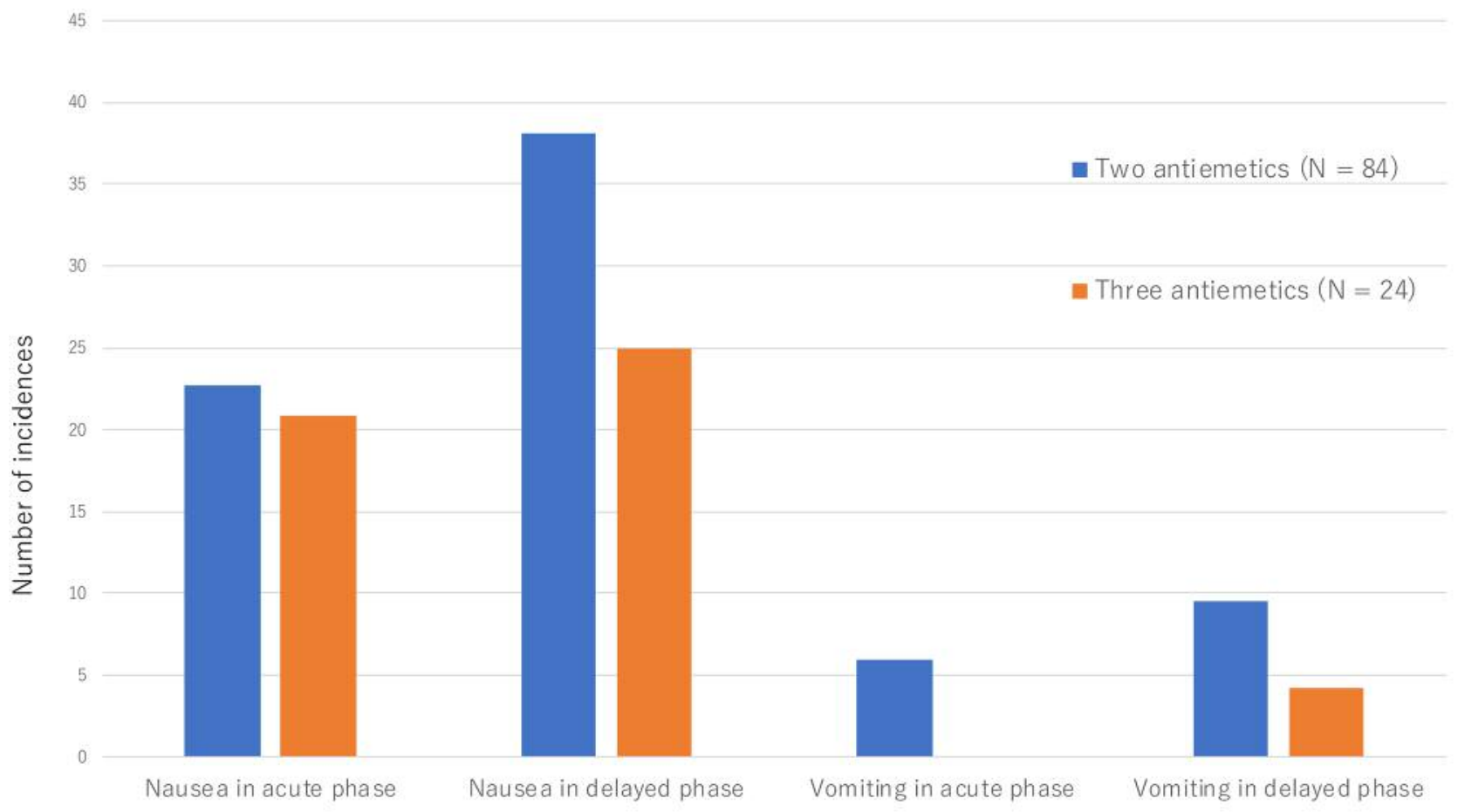

Figure 2. Comparisons of early-phase and late-phase nausea and vomiting incidence due to CHOP (cyclophosphamide, doxorubicin, vincristine, and prednisolone) therapy between patients who received double antiemetic regimens ( $5 \mathrm{HT}_{3}$ receptor antagonist and dexamethasone) and patients who received triple antiemetic regimens $\left(5 \mathrm{HT}_{3}\right.$ receptor antagonist, dexamethasone, and aprepitant).

phase were $38.1 \%$ in patients treated with double antiemetics, $25 \%$ in patients treated with triple antiemetics $(p=0.2404)$ (Figure 2).

As two-thirds of the patients received CHOP-like regimens with or without rituximab, they were compared for their CR and $\mathrm{CC}$ rates between the double and triple antiemetic regimens. Throughout the study period from day 1 to day 7 , the $\mathrm{CR}$ and $\mathrm{CC}$ rates were increased by $8.6 \%$ and $13.9 \%$, respectively, for triple antiemetic regimens versus double antiemetic regimens (no statistical significance) (Figure 3).

CINV risk factors. The risk factors for CINV did not differ between patients with haematological malignancies and patients with all previously reported conditions. Female gender $(\mathrm{OR}=2.77 ; 95 \% \mathrm{CI}=1.31-5.84 ; p=0.0074)$ and young age $(\mathrm{OR}=0.96 ; 95 \% \mathrm{CI}=0.94-0.99 ; p=0.0031)$ were identified as risk factors for early-phase nausea, while female gender remained a risk factor for late-phase nausea $(\mathrm{OR}=2.20 ; 95 \%$ $\mathrm{CI}=1.22-3.95 ; p=0.0086)$ and vomiting $(\mathrm{OR}=4.97 ; 95 \%$ $\mathrm{CI}=1.57-15.69 ; p=0.0063)$. In addition to these risk factors, alcohol drinking habit was also identified as a favorable factor for late-phase nausea by univariate analysis $(\mathrm{OR}=0.40 ; 95 \%$ $\mathrm{CI}=0.20-0.83 ; p=0.0135)$. Multivariate analysis revealed that female gender $(\mathrm{OR}=3.457 ; 95 \% \mathrm{CI}=1.54-7.78 ; \mathrm{p}=0.0027)$, young age $(\mathrm{OR}=0.96 ; 95 \% \mathrm{CI}=0.93-0.98 ; \mathrm{p}=0.0015)$ and haemoglobin (per $1 \mathrm{~g} / \mathrm{dl}$ increment) $(\mathrm{OR}=1.23 ; 95 \% \mathrm{CI}=1.01$ $1.50 ; \mathrm{p}=0.0402$ ) were identified as risk factors for early-phase nausea, female gender $(\mathrm{OR}=2.24 ; 95 \% \mathrm{CI}=1.24-4.04 ; \mathrm{p}=0.0076)$ was only a risk factor for late-phase nausea, and finally female gender $(\mathrm{OR}=6.25 ; 95 \% \mathrm{CI}=1.80-21.63 ; \mathrm{p}=0.0039)$, no steroid use $(\mathrm{OR}=0.09 ; 95 \% \mathrm{CI}=0.02-0.43 ; \mathrm{p}=0.0027)$ and vincristine use $(\mathrm{OR}=5.82 ; 95 \% \mathrm{CI}=1.08-31.41 ; \mathrm{p}=0.0407)$ were identified as risk factors for late-phase vomiting.

Comparison between estimation of CINV by medical staff and actual occurrence of CINV. Estimation of early-phase nausea by medical staff matched the actual occurrence in only $14.7 \%$ of cases, while the negative predictive value was $19.8 \%$. For late-phase nausea, the positive predictive value was $24.4 \%$ and the negative predictive value was $19.3 \%$. For vomiting, the positive predictive value was $0.5 \%$ for the early phase and $1.0 \%$ for the late phase, while the negative predictive value was $87.3 \%$ for the early phase and $83.8 \%$ for the late phase.

\section{Discussion}

Unexpectedly, only $23 \%$ of patients with haematological malignancies received triple antiemetic regimens in line with the CINV guidelines for HEC. This compliance rate was much lower than that observed in the INSPIRE study (40\%) and in 


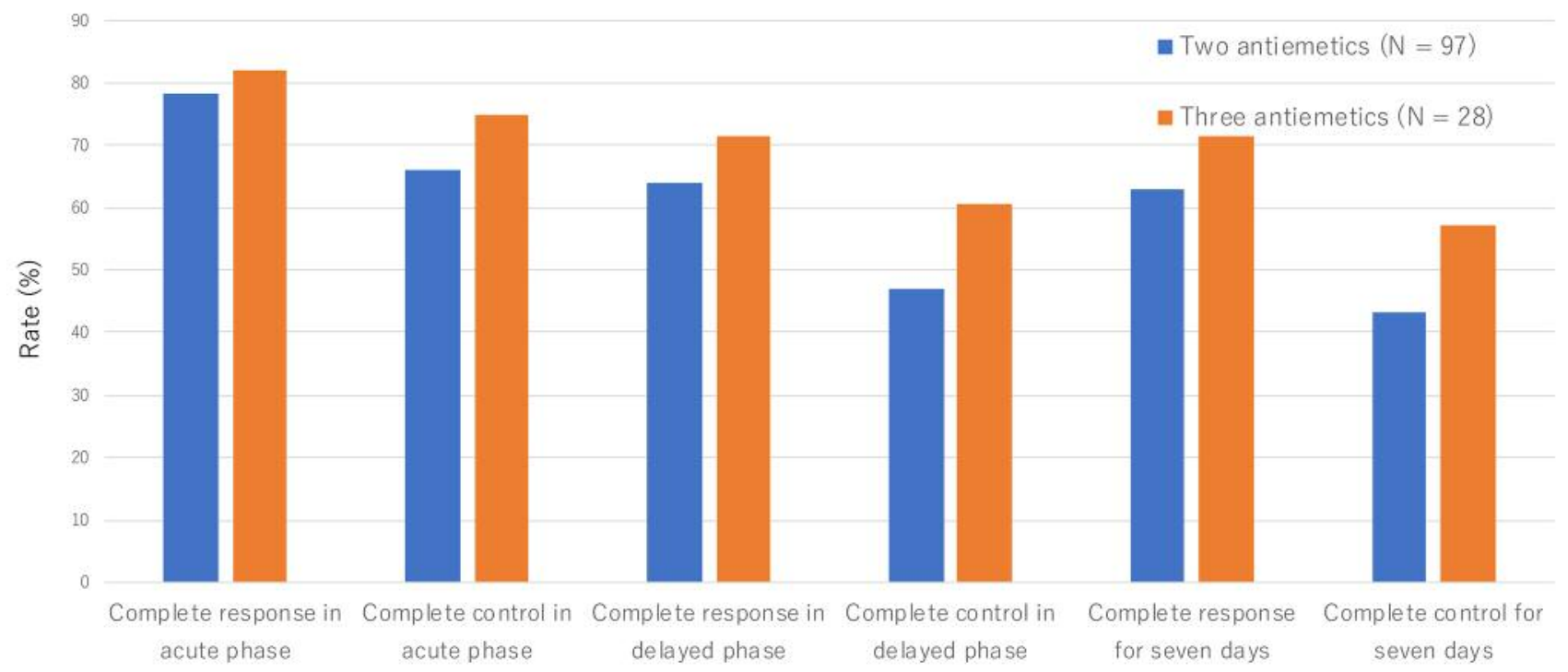

Figure 3. Complete response and complete control rates in patients who received CHOP (cyclophosphamide, doxorubicin, vincristine, and prednisolone) therapy and CHOP-like therapy.

our overall analysis including patients with haematological malignancies (74\%). Undoubtedly, the compliance rate in our overall survey was lower than expected because of the low compliance rate for triple antiemetic regimens in HEC in patients with haematological malignancies.

One reason for the low guideline compliance is thought to be the administration of high-dose glucocorticoid in regimens for patients with haematological malignancies (e.g., $100 \mathrm{mg}$ prednisolone for 5 days in the CHOP regimen). A dexamethasone dosage of up to $20 \mathrm{mg}$ /day for 3-4 days has been recommended to prevent CINV. The AC (doxorubicin plus cyclophosphamide) regimen for breast cancer is a type of HEC, and triple antiemetic therapy is recommended. CHOP consists of AC plus vincristine and prednisolone. The respective doses of doxorubicin and cyclophosphamide are 50 and $750 \mathrm{mg} / \mathrm{m}^{2}$ in CHOP, and 60 and $600 \mathrm{mg} / \mathrm{m}^{2}$ in AC. In addition to the dose differences between AC and CHOP, 5 days of treatment with high-dose prednisolone may contribute to the suppression of CINV. However, a previous clinical study (13) indicated that steroid sparing can be applied to AC therapy, because the CR rate for CINV by adding only 1 day of dexamethasone to palonosetron was not inferior to that obtained by using dexamethasone for 3 days. It is conceivable that the 5-day administration of prednisolone in the CHOP regimen may not play a significant role in achieving a clinically meaningful antiemetic effect.

As shown by the patients' risk of developing CINV, it is difficult to translate the outcomes of AC therapy in breast cancer patients into the outcomes of CHOP therapy in NHL patients, because AC is almost exclusively used in female patients and the average age at first diagnosis of breast cancer is in the fifth decade of life, while NHL has a male preponderance and is generally a disease of old age.

In the present study, we compared the $\mathrm{CR}$ and $\mathrm{CC}$ rates between double and triple antiemetic regimens. Although the sample size was too small to obtain solid conclusions, there was a tendency toward improved CR and CC rates by $8.6 \%$ and $13.9 \%$, respectively, in favour of triple antiemetic therapy with CHOP for NHL. Song et al. (14) reported results for the CEOP regimen, in which the doxorubicin in CHOP was replaced with epirubicin. The CR rate in patients treated with aprepitant plus ondansetron and prednisone was $76.5 \%$, being superior to the CR rate of $56.0 \%$ obtained by the combination of ondansetron and prednisone in patients with NHL treated by CHOP. Further studies are needed to clarify the difference in CINV suppression rates between triple and double antiemetic regimens with $\mathrm{CHOP}$ for lymphomas, because epirubicin may be less toxic than doxorubicin (15). In the Multinational Association of Supportive Care in Cancer/European Society for Medical Oncology antiemetic guidelines, one of the criteria for introducing clinical study data is $10 \%$ improvement in CINV (16). Thus, a prospective randomized trial is needed to confirm the superiority of triple antiemetic therapy over double antiemetic therapy for the CHOP regimen.

Another possibility is hesitation by haematologists to use multiple antiemetic drugs. Many haematologists use high doses of antineoplastic agents, especially for acute leukaemia and stem cell transplantation, which induce severe bone marrow suppression requiring frequent transfusions, oral 
mucositis, diarrhoea, and severe infections. These complications are sometimes life-threatening, while CINV itself is not. Patients with haematological malignancies need both oral and parenteral drugs to overcome these lifethreatening conditions. Therefore, haematologists may try to reduce the total number of drugs used for their patients. Medical cost is another important issue, because newly developed antiemetics are quite expensive. Although medical costs and health insurance systems differ among countries, the cost-effectiveness of using aprepitant is reportedly good in Germany (17), the United States (18), the United Kingdom (19), and Hong Kong (20).

Prediction of CINV by haematologists is an important factor. The positive and negative predictive values for nausea were both $<20 \%$, meaning that although $>80 \%$ of patients were predicted to develop nausea after chemotherapy, they actually experienced little sickness in contrast to the expectation of medical staff. The issue of whether this overestimation of CINV by medical staff was translated into more extensive antiemetic measures remained unclear. Medical staff may have considered that CINV would not be sufficiently severe to justify prophylactic NK1RA use, or may have ignored patients' complaints.

Nevertheless, CINV is a major side-effect of cancer chemotherapy. It not only makes patients feel sick, but also reduces their amount of oral intake, leading to dehydration and poor nutrition. The doses of antineoplastic agents need to be reduced, and the treatment interval may need to be prolonged. The ultimate goal of cancer treatment (cure or long-term complete remission) cannot be achieved if CINV is severe. Based on the present analysis of our national survey data and the above-mentioned report by Song et al. (14), young (presumably <65 years) female patients with NHL who are scheduled to receive CHOP therapy should be considered good candidates for triple antiemetic therapy instead of double antiemetic therapy.

\section{Funding}

The study was funded by a Research Grant provided by the Public Health Research Foundation (Tokyo, Japan).

\section{Authors' Contributions}

Conception and design: Kazuo Tamura, Kiyohiko Hatake; Provision of study materials or patients: Isao Yoshida, Kazuo Tamura, Toshihiro Miyamoto, Yasushi Takamatsu, Yasuhito Nanya, Itaru Matsumura, Moritaka Gotoh, Tadahiko Igarashi, Tsutomu Takahashi, Keisuke Aiba, Kyoya Kumagai, Kenichi Ishizawa, Naoki Kurita, Noriko Usui; Collection and assembly of data: All authors; Data analysis and interpretation: Isao Yoshida, Kazuo Tamura, Mototsugu Shimokawa; Manuscript writing: All authors; Final approved of manuscript: All authors; Accountable for all aspects of the work: All authors.

\section{Conflicts of Interest}

IY: Celege, Takeda, Taiho, Bristol-Myers Squibb, Mochida, Jansen, MSD, Shire, Mundi Pharma (Lecture); Chugai(Grant, lecture); Kyowa Hakko Kirin (Grant, lecture, consulting). TM, MS, YN, MG, TI, TT, KK, NK, NU declare no conflict of interest. KT: Kyowa Hakko Kirin, Ono, Eli Lilly Japan KK (honoraria, lecture). YT: Takeda, Chugai, Kyowa Hakko Kirin, Ono, Astellas, Taiho, Bristol-Myers Squibb, Pfizer, Taisho Toyama (Grant). IM: Chugai, Ono (Grant). KA: Taiho (Honoraria, lecture). KI: Kyowa Hakko Kirin, Takeda (Grant); Novartis, Chugai, Kyowa Hakko Kirin, Pfizer, Janssen (honoraria, lecture). KH: Abbvie, Gilead, Celgene, Solasia Pharma, Pfizer, BristolMyers squibb, Janssen, Ono, Chugai, Taiho, Kyowa Hakko Kirin, Takeda (Grant); Takeda, Celgene, Taiho (Honoraria, lecture).

\section{Acknowledgements}

The Authors thank the study participants, clinicians, and associated medical personnel. We thank a member of the Scientific Committee, Toshiaki Saeki, and members of the Executive Council, Masaki Kitajima, Yoshihiko Maehara, and Koichi Hirata, for their invaluable suggestions.

\section{References}

1 Navari RM and Aapro M: Antiemetic prophylaxis for chemotherapy-induced nausea and vomiting. N Engl J Med 374(14): 1356-1367, 2016. PMID: 27050207. DOI: 10.1056/ NEJMra 1515442

2 DeVita VT Jr. and Chu E: A history of cancer chemotherapy. Cancer Res 68(21): 8643-8653, 2008. PMID: 18974103. DOI: 10.1158/0008-5472.CAN-07-6611

3 Takeuchi H, Saeki T, Aiba K, Tamura K, Aogi K, Eguchi K, Okita K, Kagami Y, Tanaka R, Nakagawa K, Fujii H, Boku N, Wada M, Akechi T, Udagawa Y, Okawa Y, Onozawa Y, Sasaki H, Shima Y, Shimoyama N, Takeda M, Nishidate T, Yamamoto A, Ikeda T and Hirata K: Japanese society of clinical oncology clinical practice guidelines 2010 for antiemesis in oncology: Executive summary. Int J Clin Oncol 21(1): 1-12, 2016. PMID: 26081252. DOI: $10.1007 / \mathrm{s} 10147-015-0852-1$

4 Hesketh PJ, Grunberg SM, Gralla RJ, Warr DG, Roila F, de Wit R, Chawla SP, Carides AD, Ianus J, Elmer ME, Evans JK, Beck K, Reines S, Horgan KJ and Aprepitant Protocol 052 Study Group: The oral neurokinin-1 antagonist aprepitant for the prevention of chemotherapy-induced nausea and vomiting: A multinational, randomized, double-blind, placebo-controlled trial in patients receiving high-dose cisplatin--the aprepitant protocol 052 study group. J Clin Oncol 21(22): 4112-4119, 2003. PMID: 14559886. DOI: 10.1200/JCO.2003.01.095

5 Hatta Y, Mizuta S, Matsuo K, Ohtake S, Iwanaga M, Sugiura I, Doki N, Kanamori H, Ueda Y, Yoshida C, Dobashi N, Maeda T, Yujiri T, Monma F, Ito Y, Hayakawa F, Takeuchi J, Kiyoi H, Miyazaki Y and Naoe T: Final analysis of the jalsg ph+all202 study: Tyrosine kinase inhibitor-combined chemotherapy for ph+all. Ann Hematol 97(9): 1535-1545, 2018. PMID: 29694642. DOI: $10.1007 / \mathrm{s} 00277-018-3323-8$

6 Coiffier B: Rituximab in the treatment of diffuse large b-cell lymphomas. Semin Oncol 29(1 Suppl 2): 30-35, 2002. PMID: 11842386. 
7 Miyata Y, Yakushijin K, Inui Y, Imamura Y, Goto H, Mizutani Y, Kurata K, Kakiuchi S, Sanada Y, Minami Y, Kawamoto S, Yamamoto K, Ito M, Tominaga R, Gomyo H, Mizuno I, Nomura T, Kitagawa K, Sugimoto T, Murayama T, Matsuoka H and Minami H: A prospective study of the antiemetic effect of palonosetron in malignant lymphoma patients treated with the chop regimen. Int J Hematol 104(6): 682-691, 2016. PMID: 27612464. DOI: 10.1007/s12185-016-2089-9

8 Takahashi T, Kumanomidou S, Takami S, Okada T, Adachi K, Jo Y, Ikejiri F, Onishi C, Kawakami K, Miyake T, Inoue M, Moriyama I, Suzuki R and Suzumiya J: A retrospective study of r-chop/chop therapy-induced nausea and vomiting in nonhodgkin's lymphoma patients: A comparison of intravenous and oral 5-ht3 receptor antagonists. Int J Hematol 104(3): 378-383, 2016. PMID: 27312042. DOI: 10.1007/s12185-016-2041-z

9 Tamura K, Aiba K, Saeki T, Nakanishi Y, Kamura T, Baba H, Yoshida K, Yamamoto N, Kitagawa Y, Maehara Y, Shimokawa M, Hirata K, Kitajima M and Japan CSGo: Testing the effectiveness of antiemetic guidelines: Results of a prospective registry by the cinv study group of Japan. Int J Clin Oncol 20(5): 855-865, 2015. PMID: 25681876. DOI: 10.1007/s10147-015-0786-7

10 Tamura K, Aiba K, Saeki T, Nakanishi Y, Kamura T, Baba H, Yoshida K, Yamamoto N, Kitagawa Y, Maehara Y, Shimokawa M, Hirata K, Kitajima $M$ and Japan CSGo: Breakthrough chemotherapy-induced nausea and vomiting: Report of a nationwide survey by the cinv study group of japan. Int $\mathrm{J}$ Clin Oncol 22(2): 405-412, 2017. PMID: 27909835. DOI: $10.1007 /$ s10147-016-1069-7

11 Baba Y, Baba H, Yamamoto S, Shimada H, Shibata T, Miyazaki T, Yoshikawa T, Nakajima Y, Tsuji Y, Shimokawa M, Kitagawa Y and Aiba K: Chemotherapy-induced nausea and vomiting is less controlled at delayed phase in patients with esophageal cancer: A prospective registration study by the cinv study group of Japan. Dis Esophagus, 2016. PMID: 27001532. DOI: 10.1111/ dote.12482

12 Nitta H, Baba H, Sugimori K, Furuse J, Ohkawa S, Yamamoto K, Minami H, Shimokawa M, Wakabayashi GO, Aiba K and Japan CSGo: Chemotherapy-induced nausea and vomiting in patients with hepatobiliary and pancreatic cancer treated with chemotherapy: A prospective observational study by the cinv study group of japan. Anticancer Res 36(4): 1929-1935, 2016. PMID: 27069182

13 Aapro M, Fabi A, Nole F, Medici M, Steger G, Bachmann C, Roncoroni S and Roila F: Double-blind, randomised, controlled study of the efficacy and tolerability of palonosetron plus dexamethasone for 1 day with or without dexamethasone on days 2 and 3 in the prevention of nausea and vomiting induced by moderately emetogenic chemotherapy. Ann Oncol 21(5): 1083 1088, 2010. PMID: 20080830. DOI: 10.1093/annonc/ mdp584
14 Song Z, Wang H, Zhang H, Zhao K, Zhang $M$ and Yang F: Efficacy and safety of triple therapy with aprepitant, ondansetron, and prednisone for preventing nausea and vomiting induced by $\mathrm{r}-$ ceop or ceop chemotherapy regimen for non-hodgkin lymphoma: A phase 2 open-label, randomized comparative trial. Leuk Lymphoma 58(4): 816-821, 2017. PMID: 27545191. DOI: $10.1080 / 10428194.2016 .1213838$

15 Masaoka T, Shibata H, Sampi K, Hirota Y, Yoshida Y, Chiba Y, Shirakawa S, Kobayashi T, Toki H and Tamura K: A phase II study of epirubicin in malignant lymphoma. Gan To Kagaku Ryoho 13(8): 2606-2611, 1986. PMID: 3461747.

16 Einhorn LH, Rapoport B, Navari RM, Herrstedt J and Brames MJ: 2016 updated mascc/esmo consensus recommendations: Prevention of nausea and vomiting following multiple-day chemotherapy, high-dose chemotherapy, and breakthrough nausea and vomiting. Support Care Cancer 25(1): 303-308, 2017. PMID: 27815710. DOI: 10.1007/s00520-016-3449-y

17 Lordick F, Ehlken B, Ihbe-Heffinger A, Berger K, Krobot KJ, Pellissier J, Davies G and Deuson R: Health outcomes and costeffectiveness of aprepitant in outpatients receiving antiemetic prophylaxis for highly emetogenic chemotherapy in germany. Eur J Cancer 43(2): 299-307, 2007. PMID: 17134890. DOI: 10.1016/j.ejca.2006.09.019

18 Moore S, Tumeh J, Wojtanowski S and Flowers C: Costeffectiveness of aprepitant for the prevention of chemotherapyinduced nausea and vomiting associated with highly emetogenic chemotherapy. Value Health 10(1): 23-31, 2007. PMID: 17261113. DOI: $10.1111 / j .1524-4733.2006 .00141 . x$

19 Humphreys S, Pellissier J and Jones A: Cost-effectiveness of an aprepitant regimen for prevention of chemotherapy-induced nausea and vomiting in patients with breast cancer in the UK. Cancer Manag Res 5: 215-224, 2013. PMID: 23950658. DOI: 10.2147/CMAR.S44539

20 Chan SL, Jen J, Burke T and Pellissier J: Economic analysis of aprepitant-containing regimen to prevent chemotherapy-induced nausea and vomiting in patients receiving highly emetogenic chemotherapy in Hong Kong. Asia Pac J Clin Oncol 10(1): 8091, 2014. PMID: 24571059. DOI: 10.1111/ajco.12170 